\title{
O DISCURSO MIDIÁTICO E A (IN) COERÊNCIA DA RESPOSTA PUNITIVA DO ESTADO BRASILEIRO
}

\author{
THE MEDIA SPEECH AND (IN) COHERENCE OF PUNITIVE RESPONSE FROM \\ BRAZILIAN STATE
}

Evandro Soares

Mestrando pelo Instituto Brasiliense de Direito Público - IDP

E-mail:ess1965br@hotmail.com

Recebido em: 06/03/2017

Aprovado em: 04/02/2018

\begin{abstract}
RESUMO: O presente artigo tem por objeto apreciar a teoria garantista e os efeitos do discurso midiático sobre o Estado brasileiro. O estudo estará focado na relação entre a criminologia midiática (incluídas as respostas estatais punitivas) e os direitos e garantias fundamentais. Justifica-se o estudo diante das discussões sob o enfoque doutrinário e prático no cenário nacional, uma vez que o assunto encontra pertinência e interesse jurídico, além de trazer essa temática para o debate no atual cenário jurídico brasileiro e internacional. Dessa forma, serão apresentadas, em uma apertada síntese, noções do modelo garantista no direito penal, bem como aspectos inerentes do discurso midiático, a fim de proporcionar ferramentas mínimas de conhecimento sobre o tema. A seguir, trata-se do poder que a criminologia midiática exerce sobre os agentes estatais, apresentando recortes de casos concretos do cenário brasileiro. Por fim, o problema proposto estará calcado na breve análise da influência da criminologia midiática sobre o sistema estatal brasileiro, na geração de respostas punitivas e no seu impacto nos direitos e garantias fundamentais. A metodologia adotada foi a pesquisa bibliográfica, com uma ampla revisão das obras já publicadas.
\end{abstract}

Palavras-Chave: Teoria Garantista. Criminologia midiática. Estado punitivo. Politica Criminal.

ABSTRACT: The objective of this article is to make a critical analysis of the garantista theory and effects of mediatic discourse about Brazilian State. This study will be focused on the relationship between mediatic criminology (included punitive state responses) and fundamental rights and guarantees. The study is justified in the face of discussions under the doctrinal and practical approach in the national scenario, since the subject is of legal relevance and interest, as well as covering the current debate on the Brazilian legal scene, and perhaps international. In this way, concepts ofgarantistamodel into criminal law, as well asaspects of themediatic discoursewill be discussed in a short synthesis to provide minimum knowledge tools on the topic. Then, go for the power of mediatic criminology that it exercises over State agents, showingcutoutsof concrete caseson the Brazilian scene. Finally, the proposed issue is based upon a briefanalysis of the influenceof mediatic criminology about Brazilianstate system, generating appropriate responsespunitive and their impactonfundamental rights and guarantees. Regarding Methodology, inductive logic was adopted through bibliographic research with an extensive review of the works already published.

Key-Words:Garantista Theory. Mediatic Criminology.Punishment State. Criminal Policy. 
SUMÁRIO: Introdução; 1. Considerações iniciais entre o direito penal sob a perspectiva Garantista e o discurso midiático; 2. A criminologia midiática e a sua influência nas esferas do poder estatal; 3. Uma breve análise de casos concretos do cenário brasileiro; Conclusão; Referências.

\section{INTRODUÇÃO}

“- Atira, meu filho; é bandido!". Na busca de elevar os índices de audiência da Rede Record, o apresentador Marcelo Rezende, do programa Cidade Alerta, durante a transmissão ao vivo de uma cena de violência policial (Polícia Militar de São Paulo), ocorrida no dia 23 de janeiro de 2016, proferiu uma das frases que está intrinsecamente viva no imaginário do brasileiro comum: a justiça rápida e imediata com a condenação à morte dos suspeitos de roubo (FROTA, 2016).

Certos programas de televisão, como o citado, e outros meios midiáticos, como jornais, rádios, redes sociais, dentre outros, estão buscando influenciar a sociedade brasileira, ao difundir a cultura do medo, da impunidade e da violência sem fim.

O Estado brasileiro (com ênfase nos seus Poderes constituídos) é retratado pelos meios mencionados como ineficiente e ineficaz em face do crime, pintado com as cores da onipresença, da onipotência e da brutalidade sem limites, a que todos os brasileiros estão expostos no seu cotidiano, fruto da forma "tépida" de responder aos inúmeros casos violentos que ocorreram no território nacional.

Diariamente, os cidadãos são levados a acreditar, por intermédio da mídia, de todas as tendências, que o aparato policial é despreparado e opressor, as leis são ineficientes e graciosas para os chamados "bandidos", "marginais" e "criminosos" e, por fim, que a justiça favorece a impunidade para os influentes e abastados, em detrimento das camadas mais pobres da sociedade.

Essa situação, associada às estruturas estatais existentes, induz a uma resposta que, por vezes, é imediatista, sem passar pela necessária discussão entre a sociedade e todas as esferas do poder nacional, gerando interpretações e decisões judiciais casuísticas e distorcendo o conceito pleno de justiça.

Contrapondo-se a esse estado caótico e arbitrário, o professor italiano Ferrajoli (2002) apresenta o direito penal sob a perspectiva garantista, que, em apertada síntese, se fundamenta na tutela das liberdades da pessoa humana, em oposição ao exercício do arbítrio, pois a violação dos direitos e garantias fundamentais tem sido uma normalidade no dia a dia dos brasileiros, influenciada, inúmeras vezes, pelo calor das emoções dos acontecimentos.

Nesse sentido, este artigo pretende apresentar as considerações da relação entre o direito penal, sob a perspectiva garantista, e o discurso midiático. $\mathrm{Na}$ sequência, busca abordar a criminologia midiática e sua influência nas esferas dos poderes nacionais. Por fim, uma breve análise de um caso concreto é apresentada.

Para o desenvolvimento do texto, foram implementadas algumas estratégias de investigação, tais como levantamento e análise de material bibliográfico entre autores nacionais e estrangeiros que abordam o assunto, mostrando a dicotomia existente na forma de o Estado responder às demandas do poder midiático em face dos casos de violência no País.

A metodologia adotada foi a pesquisa bibliográfica, com vistas a descrever os fatos existentes relacionados com o problema proposto, que é evidenciar a influência da criminologia midiática sobre o sistema estatal brasileiro, na geração de respostas punitivas descritivas e o conflito gerado na observância dos direitos fundamentais.

Por fim, o objetivo do trabalho é mostrar, a partir de um caso concreto, a possível influência do discurso midiático na atuação do Estado em proporcionar uma resposta punitiva, considerada "adequada" ao crime de elevada repercussão na sociedade brasileira. 


\section{CONSIDERAÇÕES INICIAIS ENTRE O DIREITO PENAL SOB A PERSPECTIVA GARANTISTA E O DISCURSO MIDIÁTICO}

O modelo do garantismo penal, preconizado por Ferrajoli em sua obra "Direito e Razão: teoria do garantismo penal", está fundamentada em diversos princípios, tais como a "legalidade estrita, a materialidade e a lesividade dos delitos, a responsabilidade pessoal, o contraditório entre as partes, a presunção de inocência” (FERRAJOLI, 2002, p. 30).

Dentre os princípios citados, será exposto o da legalidade estrita, que se trata de uma técnica legislativa própria, cujo escopo é excluir qualquer tipo ou forma de ação discriminatória e arbitrária. Em outras palavras, na abordagem do Direito Penal relativa ao seu aspecto punitivo, o direcionamento da sua aplicação deve ter como objetivo os eventos que redundaram na prática delituosa e não determinados grupos sociais, religiosos ou estrangeiros.

Em um passado não tão distante, já havia uma agravante, por que não dizer, uma condenação prévia de pessoas que pertenciam a determinados grupos minoritários, como os já citados. Por exemplo, cita-se que, na metade do século XX, em alguns países europeus, a suspeita de um cigano ter cometido um determinado delito, por ser ele desse grupo social, poderia redundar em condenação prévia.

O presente princípio afasta da esfera penal o emprego dos costumes, da analogia, dos princípios gerais do direito e de outras fontes do direito na confecção de tipos penais não elencados em lei.

Na realidade, o princípio da legalidade estrita limita a atuação do jus puniendi, pois cerceia a discricionariedade do juiz, deixando-o restrito às normas legais, à classificação da conduta criminosa e às suas sanções, afastando atitudes e interpretações nocivas no decurso do julgamento:

Constitui, portanto, constitucionalmente, uma poderosa garantia política para o cidadão, expressiva do imperium da lei, da supremacia do Poder Legislativo - e da soberania popular -, sobre os outros poderes de Estado, de legalidade da atuação administrativa e da escrupulosa salvaguarda dos direitos e liberdade individuais. (QUEIROZ, 2001, p 22.)

Assim, portanto, o princípio da legalidade estrita não acolhe as chamadas normas constitutivas $^{1}$ para a anomalia passível a sanção, pois estaria incorrendo em atos arbitrários e discriminatórios já citados, mas as normas regulamentares que estabelecem as respostas punitivas baseadas no desvio da conduta e do seu comportamento:

[...], portanto, não admite normas que criam ou constituem ipso jure as situações de desvio sem nada prescrever, mas somente regras de comportamento que estabelecem uma proibição, quer dizer, uma modalidade deontica, cujo conteúdo não pode ser mais do que uma ação, e a respeito da qual seja aleticamente possível tanto a omissão quanto a comissão, uma exigível e a outra obtida sem coação e, portanto, imputável a culpa ou responsabilidade de seu autor. (FERRAJOLI, 2002, p. 31).

Logo, a norma, e somente ela, poderá estabelecer o elo entre o fato e a pena, portanto a resposta punitiva do Estado deverá estar circunscrita à descrição legal das condutas consideradas criminosas, impondo-lhe a pena prevista no tipo penal correspondente, nullum crimen, nulla poena sine previa lege.

\footnotetext{
${ }^{1}$ Segundo alguns autores, as normas constitutivas são enquadradas, também, como normas definitórias ou determinativas, conforme proposta por G. H. von Wright (1963), em sua obra Norma e Ação.
} 
No Brasil, somente a União, por intermédio do Congresso Nacional, detém a competência (exclusiva) para formular em matéria penal, devendo observar a experiência dos legisladores e a realidade nacional, bem como os princípios constitucionais do processo legislativo, buscando respostas aceitáveis aos conflitos sociais, sem deixar de preservar a segurança jurídica do cidadão em face do sistema legal existente.

Assim, o Estado estabelece as condutas que deverão ser proibidas, por serem nocivas aos bens jurídicos essenciais à vida, devendo a sua prática redundar na aplicação de uma punição (pena).

Em outras palavras, apenas a lei emanada do poder Legislativo tem a capacidade de determinar quais são as condutas consideradas criminosas, afastando outras fontes que pretendam definir crimes ou até cominar penas. Então, somente o legislador possui a competência de determinar as práticas consideradas delituosas.

Finalizando, o princípio da legalidade estrita (FERRAJOLI, 2002, p. 31) exige que todos os demais princípios garantistas ${ }^{2}$ estejam presentes na lei, sendo, portanto, uma doutrina complexa metalegal, que não envolve somente a sua aplicação pelo juiz e a sua elaboração pelo Poder Legislativo, mas também a observância de todos os requisitos necessários à preservação dos direitos e garantias fundamentais na sua condução.

No entanto, o modelo garantista vem sofrendo pesadas críticas, pois "o excesso de proteção" à pessoa do infrator está gerando uma sensação de impunidade diante do crime.

A narrativa do medo, a aparência irreal da debilidade do Estado e a sensação de insegurança são alguns dos ingredientes que estão sendo amplamente difundidos pelos meios de comunicação de massa, os quais atuam conforme o seu interesse sobre a sociedade brasileira. Ela vivencia uma situação de vitimização em face do aumento dessa violência, exigindo respostas efetivas de uma política criminal estatal clara e visível.

Essa influência midiática tem gerado controvérsias e discussões. Destaca-se, nesse contexto, Eugenio Raúl Zaffaroni (2012), que, no seu livro "A palavra dos mortos: conferências de criminologia cautelar", aborda o tema sob a ótica da chamada criminologia midiática. Em apertada síntese, Zaffaroni descreve a construção (e a desconstrução) pela mídia de polos que reúnem, de um lado, o bem, e de outro o mal, traçando características próprias para cada um:

A criminologia midiática cria a realidade de um mundo de pessoas decentes frente a uma massa de criminosos, identificada através de estereótipos que configuram um eles separado do resto da sociedade, por ser um conjunto de diferentes e maus. $\mathrm{O}$ eles da criminologia midiática incomodam, impedem de dormir com as portas e janelas abertas, perturbam as férias, ameaçam as crianças, sujam por todos os lados e por isso devem ser separados da sociedade, para deixar-nos viver tranquilos, sem medos, para resolver todos os nossos problemas. Para tanto, é necessário que a polícia nos proteja de suas ciladas perversas, sem qualquer obstáculo nem limite, porque nós somos limpos, puros e imaculados. (ZAFFARONI, 2012. p. 307).

O discurso midiático promove no imaginário da sociedade brasileira uma política de incertezas em torno de sua segurança física e moral, em face da criminalidade "cada vez crescente e impune ${ }^{3}$." Diante de problemas sociais complexos, a mídia procura apresentar uma reposta simplória e rápida, fruto da "fragilidade e impassividade" ${ }^{4}$ das instituições estatais em responder com efetividade à prática do delito, gerando o chamado Direito Penal Simbólico, como alternativa para atender a demanda do medo e terror.

\footnotetext{
${ }^{2} \mathrm{Na}$ realidade, segundo Ferrajoli, os princípios garantistas estão ligados entre si, sendo possível separar os fundamentais dos considerados derivados.

${ }^{3}$ Grifo nosso

${ }^{4}$ Grifo nosso
}

Revista de Direito Brasileira | São Paulo, SP | v. 20 | n. 8 | p. 229-241 |Mai./Ago. 2018 
A busca da pacificação nacional e a manutenção de um status de segurança aceitável exigem maior intervenção da justiça penal e, por conseguinte, a atenção de todos os setores da segurança pública e das autoridades e das esferas de governo envolvidas com a questão.

Essa situação, inflamada pelo discurso apelativo, propagandista e, por vezes, com interesses desconhecidos do aparato midiático, aumenta o nível de medo das massas, demandando medidas imediatistas, que não raro - sem o devido aprofundamento da questão, sem o necessário estudo de todas as variáveis e os seus impactos, sem a necessária discussão nos campos acadêmicos e da sociedade - promove uma política criminal deficiente, com possíveis vazios no tocante aos direitos e garantias fundamentais do cidadão.

\section{A CRIMINOLOGIA MIDIÁTICA E SUA INFLUÊNCIA NAS ESFERAS DO PODER ESTATAL}

Conforme já abordado, a sociedade brasileira vive uma sensação geral de insegurança em todos os campos e setores da vida cotidiana (desemprego, violência em todos os níveis, corrupção, descrédito e outros). A velocidade das mudanças na mentalidade do brasileiro impacta, sem dúvida, o plano moral, gerando, por vezes, uma indefinição entre herói e vilão, o certo e o errado. De acordo com Silva Sánchez (2002, p. 33), a ausência de "critérios para a decisão do que é bom e do que é mau, sobre em que se pode e em que não pode confiar, constitui uma fonte de dúvidas, incertezas, ansiedade e insegurança".

Esse cenário de incertezas se aprofunda quando da ocorrência de um fato criminoso, envolvendo ingredientes que deixam patentes os desníveis sociais dos envolvidos (autores e vítimas) e o grau de violência praticado disseminado pela variedade dos veículos de comunicação gera comoção, perplexidade, espírito vingativo e a "devida" resposta punitiva do Estado, em todas as suas esferas.

A inovação tecnológica amplia a capacidade da mídia em criar verdadeiros espetáculos, com grande dramatização, abrangendo espectadores de todos os matizes para o cenário da ocorrência do fato criminoso, fazendo-os interagirem com o acontecimento, ao trazer ao seu cotidiano e imaginário, as cenas e os atores envolvidos. Essa situação relembra Bourdieu (1997. p. 66), que confirma a assertiva proposta:

Os indivíduos percebem e trabalham o material simbólico que recebem; logo, ocorre uma variação entre as possibilidades de interferência de um meio sobre os que seus receptores vão pensar em que possa haver uma maior distorção da percepção de uma mesma mensagem.

Os meios de comunicação promovem uma seleção (filtro) das informações que deverão ser difundidos, tornando-as mais atrativas a um público ávido por uma resposta punitiva, mas em todos os casos sempre objetivando o "sensacional, o espetacular" (BOURDIEU, 1997. p. 25) e o que redunda em lucro, seja pela audiência consagrada, seja pela propaganda comercial que se agrega a informação.

Assim, como consequências geradas pela mídia, verifica-se a propagação de discursos de exceção que podem ecoar nos ouvidos receptivos dos órgãos estatais responsáveis pelas políticas criminais, influenciando as instâncias legislativas, executivas e judiciárias brasileiras.

$\mathrm{Na}$ realidade, é gerada no imaginário da sociedade a ideia de que se deve punir a qualquer custo. O Estado deve dar uma resposta altura do acontecido. O que se vê é a consagração do direito penal do inimigo, desembocando na promoção de políticas públicas voltadas para a chamada segurança cidadã, na qual são formulados mecanismos de controle 
social "deles, 5 " visando afastá-los do convívio social com aplicação cada vez mais de penas privativa de liberdade.

Essa conjuntura repercute no clamor e na prática de aumentar os efetivos policiais em todas as Unidades da Federação, reformas legislativo-penais, emparedamento do Judiciário em proferir sentenças "duras" e, claro, o aproveitamento político-eleitoral com discursos das autoridades governamentais, de todos os níveis, destacando aqueles que, sob falso pretexto, promovem respostas de impacto e de expressivo apoio popular, mesmo que maculem os direitos e as garantias individuais.

A sensação de insegurança é a ideal para que os componentes do Executivo e do Legislativo editem leis ocasionais, sem lastro fundamentado, ferindo critérios coerentes com princípios político-criminais consagrados, gerando leis inócuas e em confronto com os preceitos constitucionais vigentes.

Oportunistas de plantão nos poderes constituídos apresentam soluções mirabolantes, mas de inequívoca indisponibilidade de aplicação e execução. Por exemplo, em situações que são noticiados crimes de ordem sexual, particularmente naqueles que as vítimas são crianças, surgem debates e apresentação sobre a viabilidade da castração química como pena aos autores da conduta tipificada no direito penal.

No entanto, a despeito do exacerbado exemplo de populismo legislativo, em que o parlamentar ou o membro do Executivo apresenta a sua proposta, no anseio de responder rapidamente à sociedade com uma severa e exemplar punição, ela esbarra nas limitações que a Constituição Federal de 1988 impõe ao vedar a imposição de penas cruéis. ${ }^{6}$

Dessa forma, os poderes estatais passam a criar políticas criminais com o pragmatismo utilitarista, com a edição de normas penais intervencionistas no aparato punitivo, a fim de suprir a sua incapacidade de proporcionar uma sensação concreta de segurança, em face dos estereótipos delinquentes, criados principalmente pelo aparato midiático, visando determinar que tipos de indivíduos (ou até grupo social) serão rotulados como criminosos pelos mecanismos de controle social. $^{7}$

Sobre esse aspecto, cabe uma consideração que é observada nas soluções rápidas de caráter punitivo que o Estado apresenta para responder ao clamor popular. Alessandro Baratta (2002. p 88) discorre que os estudiosos dessa teoria (Labeling Approach, também conhecida por outros defensores como a teoria do etiquetamento) estão focados na investigação de "'quem é definido como desviante?', 'que efeito decorre desta definição sobre o indivíduo? ', 'em que condições esse indivíduo pode se tornar um objeto de definição’?' e, enfim, 'quem define quem? ,

Em seu artigo, Dias e Dias F. e Mendonça (2013, p. 389) exploram melhor o tema, apresentando uma conclusão que encerra a forma como o Estado e, por não dizer, a sociedade brasileira busca adotar condutas ou mesmo respostas punitivas:

Diante do exposto, tendo em vista que Teoria do Etiquetamento analisa principalmente os efeitos estigmatizantes sobre o indivíduo, essa é de suma importância para compreender que a "conduta desviante" é construída pela sociedade, ou seja, não se trata de "uma qualidade do ato que a pessoa comete, mas uma consequência da aplicação pelos outrosdas regras e sanções para o ofensor". Dessa forma, leva-se a crer que a mídia tem uma participação muito grande na construção desse conceito de "desvio" ${ }^{8}$. (grifos nosso)

${ }^{5}$ Zaffaroni (2012. p. 307)

${ }^{6}$ Alínea "e", inciso XVLII, artigo 50 $\mathrm{CF} / 88$.

${ }^{7}$ Teoria do labelling approach ou rotulação social, de Howard S. Becker, Edwin M. Lemert e Edwin M. Shur.

${ }^{8}$ Segundo Shecaira (2004, p. 292): o teórico Becker (BECKER, Howard S. Outsiders: estudos de sociologia do desvio. Rio de Janeiro: Zahar, 2008), a conduta desviante é originada pela sociedade. Os grupos sociais criam a desviação por meio do estabelecimento das regras cuja infração constitui desviação, e por aplicação dessas regras a

Revista de Direito Brasileira | São Paulo, SP | v. 20 | n. 8 | p. 229-241 |Mai./Ago. 2018 
Ante o exposto, verifica-se que a sociedade pode sofrer influência do discurso midiático que mostra a ausência da sensação de segurança pública em todos os níveis, na construção de estereótipos criminosos - agravando ainda mais os desníveis sociais e a desconfiança entre as classes sociais-, bem como na exigência de uma resposta punitiva exemplar das estruturas (endógenas) estatais que procuram a satisfazer imediatamente o anseio popular, mesmo em detrimento de omissões e violações aos princípios dogmáticos do direito penal.

\section{UMA BREVE ANÁLISE DE CASOS CONCRETOS DO CENÁRIO BRASILEIRO}

O presente capítulo foi elaborado com base na análise de artigos científicos publicados em tradicionais revistas especializadas do Brasil, bem como em outras obras de cunho científico, como trabalhos de conclusão de curso (TCC) e dissertações de mestrado.

O foco da análise foi aproveitar os dados tabulados, as inúmeras pesquisas qualitativas e quantitativas realizadas, bem como outras fontes de conhecimento que foram submetidas a um tipo de metodologia reconhecida e de comprovação acadêmica isenta.

Dessa forma, será analisado o artigo "O consenso punitivo no caso João Hélio", de autoria do defensor público Vinícius da Paz Leite, publicado na Revista da Defensoria Pública em 2012, que trata do caso concreto de repercussão nacional, ocorrido na cidade do Rio de Janeiro. Sobre essa apreciação, outros recortes serão inseridos e/ou apresentados para formulação de análise prevista no tema do presente artigo.

Leite (2012, p. 183) apresenta o estudo de caso da morte de um menino, fruto da prática do roubo do veículo da família na cidade citada. O autor discorre sobre o peso da influência da mídia no caso em apenso:

Não obstante, este caso chamou a atenção da mídia e a dramaticidade dessa morte foi explorada incessantemente pelos meios de comunicação. A exposição exaustiva do caso caracterizou-se como uma campanha em prol de maior segurança pública (conceito, aqui, limitado ao combate da criminalidade).

A campanha foi declarada como uma exigência cidadã de respostas oficiais por parte das autoridades públicas. Pode-se perceber que, em resposta a exigências "cidadãs" midiáticas, em prol do "bem comum", há uma pronta resposta estatal, discursiva, formal e informal, em que se percebem reverberações discursivas, reiterações do mesmo discurso midiático propulsor dessas respostas (grifos nosso).

De acordo com já abordado no presente artigo, o autor enfatiza desde o início sobre como a pressão midiática, em relação a um caso de repercussão, pode provocar um frenesi punitivo, levando à busca de uma resposta fácil e rápida na edição de uma nova lei, conforme também abordado por Dias e Menezes (2013) ao citarem Luiz Flávio Gomes: ${ }^{9}$

1) no final dos anos 80 e começo dos anos 90, em razão da onda de sequestros (do empresário Abílio Diniz, de Roberto Medida - irmão de um parlamentar, na época - etc.) veio a lei dos crimes hediondos (Lei 8.072 /1990), que aumentou penas, criou crimes, cortou direitos e garantias fundamentais etc.;

pessoas específicas é que são rotuladas como outsiders. Dentro dessa linha de raciocínio, a desviação não é uma qualidade do ato que a pessoa comete, mas uma consequência da aplicação pelos outros das regras e sanções para o ofensor.

9 GOMES, Luiz Flávio. Mídia e direito penal: em 2009 o "populismo penal" vai explodir. Disponível em <http://www.lfg.com.br> Acesso em:14 fev. 2016, p. 1. 
2) em dezembro de 1992 a atriz Daniela Perez foi assassinada brutalmente pelo casal Guilherme de Pádua e Paula Thomaz. Daniela era filha da escritora Glória Perez, que fez um movimento nacional pró-endurecimento da lei dos crimes hediondos (veio, com isso, a Lei 8.930 /1994, que incluiu o homicídio qualificado como crime hediondo);

3) em 1997 a mídia divulgou imagens chocantes de policiais militares agredindo e matando pessoas na Favela Naval (Diadema-SP); a repercussão imediata foi a edição da lei de tortura (Lei 9.455 /1997).

Ainda Leite (2012, p. 184) utiliza como caminho metodológico a frequência da evidência no sítio eletrônico G1 e no jornal $O$ Globo, ambos das Organizações Globo (segundo ele, por ser uma das mais acessadas fontes de informação). As reverberações dos discursos midiáticos ocorreram nas esferas jurídicas e legislativas, bem como nos discursos do então governador do Estado do Rio de Janeiro, Sérgio Cabral, e também na clara diferenciação na difusão entre "amigos" e "inimigos", evidentes nas alocuções citadas.

$\mathrm{Na}$ análise do discurso midiático (mídia impressa, sob a perspectiva quantitativa e qualitativa e a análise do programa "Fantástico"), o autor enfatiza a diferença do espaço físico destinado à divulgação da morte do menor nos periódicos (O Globo, Jornal do Brasil e O Dia) nos dias subsequentes ao fato (aumento abrupto da quantidade destinada nos dias citados):

08/02/07

\begin{tabular}{|c|c|c|}
\hline JORNAL & CAPA & INTERIOR \\
\hline O Globo & $30 \times 20 \mathrm{~cm}$ & 5 pág. \\
\hline JB & $24 \times 23 \mathrm{~cm}$ & 6 pág. \\
\hline O Dia & $32 \times 27 \mathrm{~cm}$ & 4 pág. \\
\hline
\end{tabular}

09/02/07

\begin{tabular}{|c|c|c|}
\hline JORNAL & CAPA & INTERIOR \\
\hline O Globo & não & $16 \times 15 \mathrm{~cm}$ \\
\hline JB & não & não \\
\hline O Dia & $10 \times 6 \mathrm{~cm}$ & $20 \times 8 \mathrm{~cm}$ \\
\hline
\end{tabular}

LEITE, 2012, p. 187

Na sua análise, Leite (2012, p. 187) infere que o "evento morte teve menos relevância que os eventos prisão dos acusados e enterro da vítima. Esta polarização sofrimento das vítimas versus punição dos criminosos será a responsável pelo incremento de espaço físico destinado ao caso pelos jornais da semana".

$\mathrm{Na}$ realidade a ênfase dada pelos jornais (punição dos criminosos e o sofrimento explorado e detalhado das vítimas) levou ao aumento dos acessos aos jornais citados, bem como ao melhor aproveitamento do evento para difundir propaganda publicitária, conforme observado pelo autor:

O grande mecanismo que se faz perceber no tocante à propaganda é a confusão entre entretenimento, informação e propaganda propriamente dita. A fluidez, a falta de limites entre a propaganda e a notícia fica clara quando da análise do jornal $O$ Globo em que mais $80 \%$ da pagina do jornal era propaganda de carro e apenas $20 \%$ era noticia sobre o roubo do carro dos pais de João Hélio. É nítido o aproveitamento propagandístico da notícia do carro roubado pelo anuncio de um carro novo, configurando-se o latrocínio um verdadeiro garoto propaganda do automóvel ali anunciado (LEITE, 2012, p. 188-9).

Isso ficou evidenciado no programa de televisão "Fantástico" durante a apresentação e a entrevista com as vítimas o conflito entre os "amigos" e os "inimigos", pois os repórteres 
envolvidos procuraram criar um elo de intimidade com as os parentes do menor morto, como se fossem seus familiares e/ou amigos bem próximos e, por outro lado, despersonalizaram os criminosos ("monstros"), deixando bem claro que a insegurança está às portas das "pessoas de bem":

Podem-se sintetizar indícios de um único discurso proferido em dois tempos por duas pessoas diferentes: o que se quer é transformar um conflito local, vivido por uma família, num conflito patrimonial nacional; sentido por todos. Generalizar o direito de propriedade como sacro até para aqueles que nada possuem. A propriedade é, discursivamente, transformada em preocupação nacional (LEITE, 2012, p. 190-1).

Além disso, a entrevista alimentou a chamada "cruzada contra a impunidade", cobrando uma atitude das autoridades da área de segurança pública em debelar de forma exemplar o crime, bem como mudanças na legislação em vigor para aumentar o efeito punitivo sobre o "outro", conforme pode se observar em fragmentos retirados do artigo e da entrevista:

Rosa Cristina: "O motivo mais importante de estarmos aqui é principalmente que os governantes tivessem alma, olhassem o João como filho, como filho, $e$ não como mais um... Ah, morreu... Amanhã outro João morre!".

[...] Rosa Cristina continua: "Não pode... Tem que mudar, tem que acabar... tem que rever a legislação! $O$ Rio de Janeiro não pode ser encarado... é um caso específico... Estados mais violentos têm que ter uma legislação específica...".

[...] Pergunta Fátima Bernardes: "Surge alguma revolta?

Mãe de João Hélio: Surge, surge uma revolta sim... Surge uma revolta porque eu vejo que não são todas as pessoas que têm uma alma boa, que têm amor no coração... eu vejo que não é assim, tem pessoas duras, tem pessoas que não têm coração, que têm uma pedra no lugar do coração... Não adianta, não tem como arrancar amor de uma criatura daquelas...". "... Aquela criatura não tinha sentimento nenhum... Você vê que o que você acha que é impossível... Não, não tem coração... Se ela ficar solta na rua ela vai fazer de novo... Vai e ainda vai rir...".

Aqui, percebe-se a total instrumentalização, pelo Fantástico, da vítima, que se transforma em especialista apta a propagar o consenso punitivo. (LEITE, 2012, p. 191-2).

Sem dúvida, o programa televisivo de abrangência nacional foi o mais impactante pela capacidade envolver os telespectadores, criando uma atmosfera de afeição e sofrimento com as vítimas e de repúdio extremo e punição severa aos criminosos, ressaltando-se que o compromisso maior que os meios de comunicação têm é com o lucro, por isso selecionam exatamente o "sensacional, do espetacular" para atingir os seus objetivos (BOURDIEU, 1997. p. 25).

Essa situação evidencia a seletividade penal já abordada que leva à criação de estereótipo criminoso, o qual consiste em um jovem de um bairro da periferia, como Zaffaroni (2012, p. 307) abordou em sua obra: "A mensagem é que o adolescente de um bairro precário que fuma maconha ou toma cerveja em uma esquina, amanhã fará o mesmo que o parecido que matou uma velhinha na saída de um banco e, portanto, é preciso isolar a sociedade de todos eles".

Assim, a agência midiática promove, simbolicamente, perante o seu público, as respostas punitivas necessárias que o Estado deverá adotar na edição de leis que poderiam solucionar o problema e a condenação dos autores com a devida pena regulada na legislação penal a ser aprovada. 
Essas "reverberações do discurso único vindicativo" (LEITE, 2012, p. 192) encontraram eco nas autoridades do Executivo e do Legislativo. O então governador do Estado do Rio de Janeiro, Sérgio Cabral, aprumou o seu discurso em solidariedade às vítimas, apresentando proposta de autonomia legislativa para os Estados que obviamente é contrária ao que rege a Constituição Federal, ou seja, o chamado discurso de oportunismo que não busca uma solução, mas apenas aproveitar o momento para fins eleitoreiros.

$\mathrm{Na}$ esfera legislativa, rapidamente políticos aproveitaram o momento par apresentar as suas proposta de criação de lei, de emenda à Constituição de 88 e de decretos legislativos, particularmente da redução da maioridade penal, uma vez que havia menores no bojo dos autores, conforme transcrito a seguir:

Enquanto o clamor punitivo de uma mensagem do Globo online, na margem superior da página, ao lado da foto de João Hélio: "Senhores senadores, senhores deputados, deem instrumentos aos nossos juízes para que eles possam ser mais severos. Precisamos de uma revisão constitucional" parece ser atendido pelos deputados Alfredo Kaefer, Fernando de Fabinho, Rodrigo de Castro, Rogério Lisboa18, entre outros que fizeram propostas de Emenda à Constituição de 88, e também pelos senadores membros da Comissão de Constituição e Justiça, que no dia 26/04/07 aprovaram a redução da maioridade penal.

Sobre a redução, também foram apresentados à Câmara três projetos de decreto legislativo, cujos teores convocavam a realização de "plebiscito para consulta popular da redução ou não da maioridade", na forma do artigo 14, inciso I da Constituição da República (LEITE, 2012, p. 193).

Com isso, o que se aduz é que os entes estatais respondem com medidas populistas, por vezes inócuas, às demandas da sociedade. Ao invés de um pensamento de bem-estar coletivo, estão preocupados com si mesmos, conforme preconizado por Zaffaroni (2007 p. 77-8):

Os políticos - presos na essência competitiva de sua atividade - deixam de buscar o melhor para preocupar-se apenas com o que pode ser transmitido de melhor e aumentar sua clientela eleitoral [...] devem optar entre aderir à publicidade da repressão e ficar na moda (tornar-se $\mathrm{cool}$ ) ou ser afastados pelos competidores internos de seus próprios partidos, que aproveitariam o flanco débil de quem se mostra antiquado e impopular, ou seja, não cool.

Prosseguindo na sua pesquisa, o autor trata com exclusividade essa reverberação midiática sobre agência judicial, particularmente no julgamento de $1^{\mathrm{a}}$ estância. Por intermédio de fragmentos retirados da sentença proferida, ${ }^{10}$ Leite (2012, p. 194), mostrou a influência do poder midiático no decorrer do julgamento, levando a juíza a adotar parte da fraseologia emocional repetida no programa "Fantástico", como "quando o trio supramencionado já estava embarcado, deu-se repentinamente a partida mediante brusca aceleração. Começou aí o suplício de pequeno João Hélio, o que estarreceu e comoveu o país (...)”.

Ao final de seu trabalho, o autor concluiu que o discurso midiático sobre o caso João Hélio, ocorrido na cidade do Rio de Janeiro, repercutiu em todo o País, influenciando o imaginário popular, bem como as diversas agências estatais (Executivo, Legislativo e Judiciário); acirrou e aprofundou ainda mais o abismo entre os "amigos" e os "inimigos", ao inferir qualidades ao primeiro e despersonalizando o segundo, com o objetivo de criar uma resposta punitiva eficiente. Sobre os efeitos desse punitivismo, Dias e Dias F. e Mendonça (2013, p.391-2) citam o posicionamento de Zaffaroni:

\footnotetext{
${ }^{10}$ Processo n. 2007.202.001808-4, TJ RJ.
}

Revista de Direito Brasileira | São Paulo, SP | v. 20 | n. 8 | p. 229-241 |Mai./Ago. 2018 
(...) são os meios de massa que desencadeiam as campanhas de 'lei e ordem' quando o poder das agências encontra-se ameaçado. Estas campanhas realizamse através da 'invenção da realidade' (distorção pelo aumento de espaço publicitário dedicado a fatos de sangue, invenção direta de fatos que não aconteceram), 'profecias que se auto-realizam' (instigação pública para a prática de delitos mediante metamensagens de 'slogans' tais como 'a impunidade é absoluta', os menores podem fazer qualquer coisa', 'os presos entram por uma porta e saem pela outra', etc; publicidade de novos métodos para a prática de delitos, de facilidades, etc.). 'produção de indignação moral' (instigação à violência coletiva, à autodefesa, glorificação de 'justiceiros', apresentação de grupos de extermínio como 'justiceiros', etc.

\section{CONCLUSÃO}

Após estudo da obra de Ferrajoli, verifica-se que a doutrina garantista é fundamentalmente teórica. Entretanto, isso não invalida a sua observância na construção de um sistema penal, em particular na função punitiva do Estado. Por outro lado, deve-se também observar o momento e a cultura do país, sem paixões momentâneas ou influências oportunistas, a fim de se evitar que o excesso de garantias descambe para a sensação de impunidade. Assim, é necessário existir equilíbrio no sistema jurídico para evitar distorções de ambos os lados.

Nesse diapasão, não se pode olvidar o papel que a mídia exerce perante a sociedade brasileira. $\mathrm{O}$ seu discurso tem influenciado a opinião pública, os agentes estatais e por que não dizer o transcurso de julgamentos, propostas de leis e decisões políticas, ao retratar de forma seletiva as cenas de violência nos noticiários policiais, promovendo uma lógica punitiva de controle social.

Os ingredientes da rotulação social estão reverberando de forma crescente e crítica nos discursos de membros das agências do sistema penal e das autoridades constituídas, direcionando os seus efeitos para a parcela da população brasileira, em especial os jovens, que vive em áreas pobres e/ou periféricas.

Do exposto, verifica-se que a mensagem retirada dos discursos da criminologia midiática é direcionada para o endurecimento das normas penais, mesmo que signifique que os direitos e garantias assegurados na Constituição Federal sejam relativizados, fruto da inexistência da sensação de segurança e do crescimento do medo e do terror, propagado pela própria mídia. Aproveitadores eleitoreiros de plantão elaboram propostas que remetem a uma falsa impressão de solução dos problemas, pois mascaram seus próprios interesses, desviando da real violência estrutural da sociedade. Logo, é necessário que estudos sejam aprofundados no sentido de identificar as reais causas da violência e, com uma ação conjunta de todos, buscar a melhor solução, observando sempre os preceitos emanados pela lei maior.

\section{REFERÊNCIAS}

ALBUQUERQUE, Lucas Palhano de. Garantismo Penal: A retroatividade da norma processual penal. Brasília: UNICEUB, 2010. (Monografia apresentada como requisito para conclusão do curso de bacharelado em Direito do Centro Universitário de Brasília).

ALVES, P. P. G.. As (in) consequências e reflexos do discurso midiático na política criminal. In: $2^{\circ}$ Congresso Internacional de Direito e Contemporaneidade, 2013, Santa Maria. Edição 2013 GT3 Sistema penal, mídia e sociedade, 2013. v. II.

BARATTA, Alessandro. Criminologia crítica e crítica do direito penal: introdução à sociologia do direito penal. 3. ed. Rio de Janeiro: Revan, 2002. 
BECKER, Howard S. Outsiders: estudos de sociologia do desvio. Rio de Janeiro: Zahar, 2008.

BOURDIEU, Pierre. Sobre a televisão. Rio de Janeiro: Zahar, 1997.

Calabrich, Bruno. Conceito(s) de norma: uma breve análise sobre a classificação de Von Wright. Brasília: Revista de Informação Legislativa, v. 45, n. 178, P. 55-62, Abr./Jun. 2008, 04/2008. Disponível em <http://www2.senado.leg.br/bdsf/item/id/160253> Acesso em 28 de janeiro de 2016.

DIAS, Fábio Freitas; DIAS, F.; MENDONCA, T. C. Criminologia midiática e a seletividade do sistema penal. In: 2. ${ }^{\circ}$ Congresso Internacional de direito e contemporaneidade, 2013, Santa Maria.

DIAS, Felipe da Veiga; MENEZES, P. A criminologia midiática e a perpetuação da rotulação social de adolescentes pela Internet: velhos discursos punitivos em novas roupas virtuais. 2013. (Apresentação de Trabalho/Congresso).

FERRAJOLI, Luigi. Direito e razão: teoria do garantismo penal. São Paulo: Revista dos Tribunais, 2002.

FROTA, Jorge Henrique Sousa. O começo do fim para Datena e companhia? Disponível em: <http://jhfrota.jusbrasil.com.br/noticias/302872566/o-comeco-do-fim-para-datena-e-companhia > Acesso em: 28 jan. 2016.

GOMES, J. P. L.; MELO, S. D. M. O poder midiático na esfera do direito penal: repercussões de uma sociedade punitiva. Revista Transgressões: Ciências criminais em debate, v. 1, p. 66-84, 2013.

GOMES, Luiz Flávio. Mídia e direito penal: em 2009 o "populismo penal" vai explodir. Disponível em: <http://www.lfg.com.br> Acesso em: 24 ago. 2013.

LEITE, Vinícius da Paz. O consenso punitivo no caso João Hélio. São Paulo: Revista da Defensoria Pública, Ano $5 \quad$ - $\quad$ n.1 $\quad$ - 2012. Disponível em <http://www.defensoria.sp.gov.br/dpesp/repositorio/20/REVISTA. 2012.virtual.pdf>Acesso em 28 de janeiro de 2016.

QUEIROZ, Paulo de Souza. Direito penal: introdução crítica. São Paulo: Saraiva, 2001. . Direito penal: parte geral. 2. ed. São Paulo: Saraiva, 2005.

SHECAIRA, Sérgio Salomão. Criminologia. São Paulo: Revista dos Tribunais, 2004.

SILVA SÁNCHEZ, Jésus Maria. A expansão do direito penal: aspectos da política criminal nas sociedades pós-industriais. São Paulo: Revista dos Tribunais, 2002.

WERMUTH, Maiquel Ângelo Dezordi. Medo e direito penal: reflexos da expansão punitiva na realidade brasileira. v. 1. 1. ed. Porto Alegre: Livraria do Advogado, 2011.

ZAFFARONI, Eugenio Raúl. Em busca das penas perdidas: a perda de legitimidade do sistema penal. Rio de Janeiro. Editora Revan, 1991. 
. O inimigo no direito penal. Tradução de Roberto Lamarão. Rio de Janeiro: Revan, 2007. . A palavra dos mortos: conferências de criminologia cautelar. São Paulo: Saraiva, 2012. 